\title{
Caminhos da Autonomia: Grupo Reflexivo com Ex-Moradores de Rua
}

\author{
Décio José Moraes ${ }^{1}$ \\ ${ }^{1}$ Universidade Santo Amaro, SP, Brasil.
}

\author{
Cibele Mariano Vaz de Macêdo ${ }^{2}$ \\ ${ }^{2}$ Universidade Ibirapuera, SP, Brasil.
}

\begin{abstract}
Resumo: Este artigo é resultado do projeto de iniciação científica Os Caminhos da Autonomia que, através da realização de um grupo reflexivo, pretendeu promover a interação entre exmoradores de rua abrigados em um projeto social, membros de uma parcela da população em situação de vulnerabilidade, para que esses indivíduos despertassem para suas realidades pessoais a partir desse trabalho conjunto, de modo a se tornarem agentes transformadores de si mesmos na construção de sua autonomia. Para tanto, a metodologia aplicada de grupos reflexivos teve por finalidade a escuta e as identificações dos seus integrantes dentro de uma mesma problemática, buscando alternativas para suas resoluções. Realizaram-se quinze encontros programados e direcionados por temas de interesses comuns, nos quais foram relatadas suas histórias de vida de forma que se pudesse descobrir as singularidades de cada uma dessas narrativas. Os resultados alcançados apontam para o amadurecimento emocional do grupo, a descoberta de possibilidades reais de conscientização, que viabilizem caminhos de autonomia, sendo objetivo maior o de reconhecer a motivação para as mudanças de sua realidade através da sua história.
\end{abstract}

Palavras-chave: Grupo Reflexivo, Vulnerabilidade Social, Conscientização, Autonomia.

\section{Paths to Autonomy: Discussion Groups with Former Homeless People}

\begin{abstract}
This article is based on a scientific research named "Paths to Autonomy", an initiative to promote interactivity among persons currently participating in a Social Project focused on assisting groups exposed to social vulnerability. Through interactive activities developed in a Reflexive Group environment, the members of this group were stimulated to share personal life experiences to develop a sense of self perception, becoming agents able to transform themselves in order to build their own autonomy. The discussion group allowed to hear and identify participants facing troubling situations and looking for alternative solutions. Throughout 15 programmed encounters, considering common interests pointed out by the group, each member could expose their life history, stimulating the search for the singularity from each narrative. The main outcome were the improved emotional maturity of the group and the identification of real possibilities of individual awareness, leading to autonomy via inspiration provided by their own life experiences to change their life conditions.
\end{abstract}

Keywords: Discussion Groups, Social Vulnerability, Individual Awareness, Autonomy, Authenticity. 


\title{
Caminos hacia la Autonomía: Grupo Reflexivo con ex sin Techos
}

\begin{abstract}
Resumen: Este artículo es el resultado del proyecto de iniciación científica "Los Caminos hacia la Autonomía” que, por medio de la formación de un grupo reflexivo, pretendió promover la interacción entre ex sin techos abrigados por un proyecto social, miembros de una parte de la población en situación de vulnerabilidad, para que, a partir de ese trabajo conjunto, esos individuos pudieran despertar para sus realidades personales y convertirse en agentes transformadores de sí mismos en la construcción de su autonomía. Para ello, la metodología aplicada de grupos reflexivos tuvo por finalidad la escucha y las identificaciones de sus integrantes dentro de una misma problemática, buscando alternativas para sus resoluciones. Se realizaron 15 encuentros programados y dirigidos por temas de intereses comunes, en los cuales relataron sus historias de vida para que se pudiera descubrir las singularidades de cada una de esas narrativas. Los resultados alcanzados apuntan la maduración emocional del grupo, la descubierta de posibilidades reales de concientización, que hacen posibles caminos hacia la autonomía, siendo el mayor objetivo reconocer, por medio de su historia, la motivación para cambiar su realidad.
\end{abstract}

Palabras clave: Grupo Reflexivo, Vulnerabilidad Social, Concientización, Autonomía.

\section{Introdução}

As equações da realidade social somam uma conta de difícil resolução, principalmente quando nos deparamos com a desigualdade social que, de tão arraigada no cotidiano de nosso país, já parece ser algo naturalizado, comum ou normal, tamanha a banalização das situações de violência que vivemos cotidianamente.

Neste cenário, a contribuição do psicólogo social torna-se imprescindível, atuando como facilitador junto à população em situação de vulnerabilidade, ou seja, fomentando os questionamentos sobre sua vida e trazendo à tona as suas possibilidades de traçar caminhos de ruptura com o ciclo repleto de becos e viadutos, buscando uma maneira possível de tornar a autonomia uma realidade. Este artigo percorreu caminho semelhante ao empreender um grupo reflexivo que objetivou proporcionar uma situação mais favorável para que seus membros trilhassem novos rumos em suas vidas.

Nesse contexto, a pergunta proposta por Jodelet (2014): "como uma sociedade que se diz democrática permite processos de exclusão que a ameaçam?" (p. 56) tornou-se importante fio condutor da discussão proposta. O modelo de sociedade que adotamos exige uma solução mais permanente, sustentável para as desigualdades que se fazem presentes, tornando as práticas imediatistas e sem continuidade em um novo modelo com arranjos sólidos e políticas públicas protetoras para assegurar a prática da cidadania a todos, com cultura, lazer, trabalho e educação, algo que nos parece direito inerente de todo cidadão, mas que se perde em uma grande parcela da população.

Passamos a aceitar a inversão de valores éticos e morais como algo corriqueiro: diariamente nos deparamos com situações nas quais os bens materiais se sobrepõem à vida humana. A exclusão, em suas várias formas, nega ao indivíduo o exercício pleno de sua cidadania. Todo esse processo compromete algo fundamental para a existência humana: sua identidade.

A identidade entendida como o reconhecimento de algo no qual a pessoa se reconhece, que se constitui como o referencial propiciador do autoconceito e da imagem de si. Assim, para a identidade existir, ela depende de outra de que ela não dispõe, algo fora dela, mas que forneça as condições para que ela seja, o que a torna relacional. Na contemporaneidade, faz mais sentido pensar em identidades, como aponta Bauman (2005) elas apresentam uma qualidade negociável e revogável como uma atividade que se realiza por vezes e vezes, com infinitas possibilidades de configuração.

Entretanto, para o ex-morador de rua, à medida que se perdem os vínculos familiares, sociais e profissionais compromete-se a identidade; e, assim, resta a pergunta: o que eu sou diante da realidade que a mim 
se apresenta? Nesse cenário, pode ser difícil reconhecer-se enquanto pai/mãe, profissional, companheiro(a) e mais difícil ainda reconhecer-se enquanto morador(a) de rua, dependente químico(a) ou em dívida com a lei. A identidade torna-se, então, mais um dilema de sua existência.

Diante da problemática descrita, esta pesquisa se propôs a reunir quinze ex-moradores de rua, dos 150 desabrigados que viveram acampadas por um período em um terreno na região do Parque Dom Pedro I, na zona central da cidade de São Paulo e, desde setembro de 2014, foram transferidos para um espaço cedido pela Prefeitura de São Paulo denominado Autonomia em Foco II. O objetivo era formar um grupo capaz de identificar os problemas enfrentados nos âmbitos sociais e familiares, a fim de promover a conscientização sobre cidadania e direitos.

Todos os integrantes do grupo participam das ações promovidas pela organização não governamental Serviços Assistenciais Bom Jesus dos Passos (SASBJP), que tem por missão o trabalho com a população de rua e em situação de vulnerabilidade social da cidade de São Paulo.

A SASBJP possui outros serviços em parceria com a Prefeitura de São Paulo, como o Instituto de Longa Permanência de Idosos (ILPI) - Butantã, o Serviço de Acolhimento de Crianças e Adolescentes (Saica), a Moradia Inclusiva para Crianças e Adultos Especiais, os Centros de Acolhimento 24 Horas e o Autonomia em Foco II, todos voltados especificamente para esse público.

Para atender a demanda desse grupo de pessoas, o serviço Autonomia em Foco II conta com uma equipe técnica constituída por um gerente, dois assistentes sociais, um psicólogo, doze orientadores socioeducativos, equipes de manutenção, limpeza e portaria.

Desde que chegaram ao serviço, muitos desafios já foram superados, no entanto, ainda é necessário escalar mais alguns degraus e enfrentar as dificuldades de se readaptar a uma nova realidade. Nesse contexto, a criação de um grupo reflexivo objetivou possibilitar reflexões sobre essas dificuldades, como buscar um novo emprego, voltar a estudar, assumir responsabilidades com seus filhos, tudo isso visando a promoção e a identificação destes problemas nas questões de relações familiares e sociais e oportunizando o exercício da autonomia em vários âmbitos da vida.

\section{Descaminhos e caminhos da autonomia}

Este trabalho foi desenvolvido com essa parcela da população que, por condições adversas como a pobreza, vivenciaram ao longo de anos situações humilhantes impostas por uma sociedade injusta no sentido social; os descaminhos são evidenciados pela falta de uma estrutura condizente com as condições mínimas para uma vida com qualidade, ou seja, ter garantido seus direitos de lazer, estudo, trabalho digno e principalmente exercer sua cidadania participativa.

Foram essas considerações que motivaram a criação desse grupo reflexivo, que pretendeu se constituir enquanto um espaço possível de troca de experiências e emoções entre seus participantes, de forma a levá-los a experimentar novamente relações afetivas que poderiam ser agentes transformadores de suas vidas.

As diversas narrativas que surgiram nesse espaço revelaram o quanto a desigualdade perpetrada pela sociedade se faz presente no dia a dia dos participantes. Narrativas essas que se traduziram por palavras de sofrimento, envolvidas em uma perspectiva muitas vezes caótica: o total desmantelo das relações parentais, o abuso de drogas, a falta de emprego, a violência nas ruas.

A maneira como os participantes do grupo falavam era angustiante para eles, as cicatrizes deixadas pela vida na rua ainda estavam abertas. No entanto, no decorrer do grupo, o alicerce para a construção de novos entendimentos foi alavancado por essa experiência neste processo de transformação social, de não querer mais viver a margem da sociedade.

"Caminhos da Autonomia", no plural como sugere o título deste artigo, faz referência às inúmeras possibilidades de se pensar a autonomia. Para ex-moradores de rua, abrigados em um projeto social, quase sempre a autonomia está relacionada ao fato de conseguir uma moradia, conseguir tratar a dependência química e "continuar limpo", concluir a escola ou formação profissional, recolocar-se no mercado de trabalho, recuperar a guarda perdida de um filho ou ainda reestabelecer os vínculos familiares. $\mathrm{O}$ desafio constitui-se justamente por reconhecer qual autonomia buscar e quais obstáculos precisam ser superados.

\section{A escuta como forma de aprendizado e conscientização}

Em função dessa realidade dura é que a escuta se tornou algo imprescindível para se encontrar o caminho de volta, para reencontrar-se consigo mesmo, ou, 
quem sabe, criar, por meio daquilo que foi dito, o que pode ser feito nessa direção. Nesse sentido, Melucci (2004) refere-se à escuta nos seguintes termos:

Estou convencido de que o mundo contemporâneo necessita de uma sociologia da escuta. Não de um conhecimento frio, que para no âmbito das faculdades racionais, mas de um conhecimento que concebe a todos como sujeitos. Não um conhecimento que cria distância, separação entre observador e observado, mas de um conhecimento que consegue reconhecer as necessidades, as perguntas, as interrogações de quem observa, e também capaz de, ao mesmo tempo, pôr verdadeiramente em contato com os outros (p. 9).

A escuta como Melucci (2004) entende contribuiu para o desenvolvimento do grupo. Esta escuta que deixa para trás a maneira egoica de ser, na qual apenas eu narro o meu pensar, existir, sentir, evidenciando a falência de alteridade. Se dermos uma chance e abrirmos os ouvidos à escuta, teremos, então, a chance de aprender mais. Se atentarmos aos sinais, que mostram a necessidade cada vez maior dessa escuta, em meio ao caos em que vivemos, evitando que se crie uma distância cada vez maior entre observado e observador, que transforma o conhecimento em algo comunitário e participativo, pode ser que tenhamos uma chance de sair dessa encruzilhada.

\section{Vínculos sociais: entre rupturas e reconstruções}

Nossa pretensão com esta pesquisa foi despertar o desejo de narrar e escutar sua própria realidade nos participantes. Bahia (2010, pp. 84-85) escreve sobre como as narrativas são mais que um método de investigação, "são formações discursivas referentes à maneira como uma sociedade se autodefine".

Contudo, as pessoas em situação de vulnerabilidade têm pouco ou nenhum espaço para narrar suas histórias, pois não só estes princípios básicos do relacionamento humano se encontram em falência no modus operandi da sociedade atual, como faz-se necessário questionar até que ponto vamos aceitar passivamente este cenário em uma sociedade que se diz democrática, mas permite a violação de direitos de grande parte de sua população?
Mariangela B. Wanderly (2014), ao analisar as metamorfoses da questão social, retoma o conceito de vínculo societal proposto por Castel (1997), entendido como uma ruptura de pertencimento: "desafiliado é aquele cuja trajetória é feita de uma série de rupturas com relação a estados de equilíbrio anteriores, mais ou menos estáveis, ou instáveis" (p. 22).

A autora considera as populações com insuficiências materiais e também aquelas fragilizadas pela instabilidade do tecido relacional, não somente em vias de pauperização, mas de desafiliação, ou seja, de perda do vínculo societal. Segundo ela, Castel (1998) afirma que "Desafiliação não é o equivalente necessariamente a uma ausência completa de vínculos, mas a ausência de inscrição do sujeito em estruturas que têm sentido" (Wanderley, 2014, p. 22).

A todo o momento fica clara não só a exclusão, mas também a desafiliação, que levam o indivíduo que não teve a chance de pertencer a uma família minimamente estruturada ser cada vez mais marginalizado. O que fazer para resolver esta equação ainda é uma incógnita, mas a criação de rede de apoio, a prática da afetividade, da alteridade poderão ser $o$ caminho para subverter a realidade daqueles que não tiveram as mesmas oportunidades.

Nesse cenário, a realização do grupo reflexivo, em consonância com as políticas públicas de assistência social, intentou justamente viabilizar um espaço no qual fosse possível reestabelecer e mesmo criar novos vínculos para a constituição de redes coletivas de apoio que pudessem auxiliar os participantes na retomada de suas vidas, seja conseguindo formação profissional, trabalho, moradia ou tratamento, por exemplo.

\section{Assistência e assistencialismo}

O que dizer da assistência quando se torna um instrumento desfavorável à autonomia? Isso é passível de acontecer quando o assistido torna-se dependente dos serviços socioassistenciais de maneira inadequada, procurando não desenvolver suas potencialidades em razão de construir um vínculo de dependência, o que acaba por tornar-se um assistencialismo, o indivíduo fica desprovido de motivação para avançar em sua trajetória, de buscar consolidar seus objetivos de autonomia, como a busca por uma recolocação no mercado de trabalho, uma internação para tratamento de dependência química, enfim, tudo o que pode levá-lo a se desvincular desse 
atendimento prestado, muitas vezes de forma benéfica, porém classifica-se, por vezes, em um entrave ao crescimento pessoal dele.

No Brasil, as primeiras políticas sociais surgiram no governo de Getúlio Vargas (1930-1945), mais como práticas provisórias e desarticuladas que políticas propriamente ditas, apesar de necessárias, objetivavam gerar certa harmonia entre as classes sociais, mas tinham pouca ou nenhuma consequência transformadora (Silva \& Corgozinho, 2011).

A assistência social tornou-se de fato direito de todos os cidadãos e dever do Estado, formando o tripé da seguridade social ao lado da saúde e da previdência, somente a partir da Constituição de 1988, que marcou o início de uma nova proteção social que estimula maior participação coletiva (Silva \& Corgozinho, 2011).

E foi só no século XXI que o Sistema Único de Assistência Social (Suas) se consolidou. Por ser uma política relativamente recente, está em constante processo de construção, reconstrução e superação do desafio de ultrapassar essas primeiras práticas assistencialistas e se estabelecer de fato enquanto política de integração, voltada à totalidade das necessidades humanas de forma geral e particular, atuando no campo da proteção e buscando a superação de situações de vulnerabilidades, riscos e violências (Ministério do Desenvolvimento Social e Combate à Fome, 2009).

O desafio de superar tais práticas foi um tema discutido durante os encontros, alguns participantes verbalizaram esse desgosto com o assistencialismo, disseram que isso acaba por acomodar o morador do projeto, deixando-o desestimulado a buscar novas oportunidades, por vezes, é como se ficasse prisioneiro desta assistência, muito provavelmente por não estar seguro de ter construído redes de apoio suficientemente fortes para ser capaz de seguir adiante.

Essa mudança acontece quando o morador se dá conta que a construção da sua autonomia como indivíduo não pode estar vinculada unicamente à rede de assistência, isso não significa que esta rede não seja importante e necessária; nesse sentido, os estudos de Paugan (2003) foram fundamentais e elucidativos por descreverem como ser saudável é benéfico para todos, dos sentimentos de não pertencimento ao local onde se mora, do status da marginalidade, da submissão aos órgãos governamentais e sobre toda angústia que a situação gera:
O jogo de sedução é possível enquanto o contrato for respeitado, isto é, enquanto o assistido respeitar as condições previstas de comum acordo com o especialista que se encarrega dele, e enquanto o assistente social acreditar que a intervenção é benéfica ao cliente. Nesse caso, o procedimento da designação não é somente nominal. A etapa que inicia a carreira moral foi ultrapassada. As consequências práticas da designação são então observáveis, já que o designador e o designado estão de acordo quanto a um projeto em comum (Paugan, 2003, p. 202).

Neste ponto da nossa reflexão, precisamos entender que não basta a tomada de consciência destes moradores inseridos em um serviço de acolhimento transitório, faz-se necessário oferecer um atendimento autônomo a cada um destes indivíduos, que considere sua história, suas necessidades e, ao mesmo tempo, pondere as questões econômicas, políticas e sociais que envolvem temas como a moradia e a dependência química, por exemplo.

\section{Metodologia}

A metodologia aqui aplicada foi a de grupos reflexivos. Através de encontros regulares, no período de setembro de 2015 a março de 2016, o grupo reflexivo "Caminhos da Autonomia" visou promover a interação entre os participantes, com intuito de ampliar suas perspectivas pessoais, seus processos de conscientização, enfim, promover a partilha de suas experiências de vida, buscando a transformação de sua realidade.

Nesse grupo, estabeleceu-se uma dinâmica na qual as identificações foram o motor para o reconhecimento dos padrões vivenciados, dentro de um mesmo contexto histórico. Esses encontros foram, de fato, substanciais no processo de superação: a partir da exposição das experiências de cada um e através do diálogo entre os participantes, criou-se um ambiente propício à reflexão.

Neste contexto, a narrativa e a escuta entre os participantes foram os mecanismos geradores de identificações fundamentais para formar os vínculos necessários ao desenvolvimento dos processos de aprendizagem de cada um; processo que se deu no exercício de reconhecer na figura do outro o reflexo de si mesmo, e diante disto, a representação da sua subjetividade, das suas emoções e seus sentimentos. 
Para Dellarosa (citado por Coronel, 2007), o grupo reflexivo segue algumas diretrizes, quais sejam: ele não objetiva cumprir uma função terapêutica, antes disso pretende, a partir da discussão da problemática na qual os participantes estão inseridos, possibilitar que as tensões vividas sejam elaboradas enquanto uma experiência formativa que possibilite descobrir e modificar um padrão de funcionamento. Para tanto, reúne-se preferencialmente um número entre dez e quatorze pessoas, sem temas prefixados, embora busque manter uma reflexão dentro dos interesses dos participantes.

Foi através dessa perspectiva que pudemos avaliar o quanto o grupo reflexivo, apesar de não ter finalidade terapêutica, pôde exercer esta função para os participantes, principalmente quando se criou um vínculo e uma identificação entre seus membros, formando redes coletivas de apoio mútuo. Este tipo de grupo reflexivo baseia-se em princípios éticos, morais e de sigilo.

O grupo contou com quinze participantes de ambos os sexos, sendo oito homens e sete mulheres, maiores de dezoito anos, ex-moradores de rua que vivem no serviço de acolhimento institucional para famílias e indivíduos em situação de rua, uma unidade do âmbito da proteção social especial de alta complexidade, com atendimento 24 horas, chamada Autonomia em Foco II, instituição mantida pela Prefeitura da Cidade de São Paulo e gerida pela organização não governamental Serviços Assistenciais Bom Jesus dos Passos, localizada na Baixada do Glicério, na região central da cidade.

Atualmente, vivem no serviço 150 pessoas, entre famílias e pessoas solteiras, estrangeiros e brasileiros, crianças e adultos, sendo que alguns estão no serviço há mais de três anos. Essas pessoas chegam ao serviço encaminhadas pelo Centro de Referência Especializada em Assistência Social (Creas). Além da moradia, com acesso à cozinha e banheiros, elas participam de oficinas de panificação, costura, atividades esportivas, recebem encaminhamento para tratamento médico e psicológico e encaminhamento para escola, cursos profissionalizantes e vagas de trabalho.

A instituição foi escolhida por tratar-se de um espaço onde um dos pesquisadores atua como consultor autônomo na capacitação dos orientadores do serviço. Assim, a realização do grupo reflexivo foi proposta pela pesquisa de campo de um projeto de iniciação científica, aprovado pelo Comitê de Ética e Pesquisa. Para a divulgação do grupo, foram distribuídos na instituição cartazes que continham os objetivos que seriam trabalhados e convidando os moradores a participarem, o convite também foi feito durante a assembleia organizada pelos moradores semanalmente.

A seleção dos participantes foi feita a partir do interesse dos moradores em aderir à proposta de interagir em um grupo reflexivo. A entrevista prévia para a seleção dos integrantes foi realizada em uma das assembleias do projeto. Na entrevista foram apresentados novamente os objetivos do grupo e perguntado se o morador tinha disponibilidade para participar nos dias e horários propostos.

O grupo foi organizado de forma autônoma e independente, permitindo a seus integrantes opinar livremente sobre os temas discutidos ao longo dos encontros, bem como estavam livres para deixá-lo, fosse por questões de mudança ou desistência. Nestes casos, houve o reforço do convite para que outros moradores participassem, mas sem ultrapassar o número limite de doze participantes presentes, e com a aprovação dos demais membros.

Foram quinze encontros, com temáticas predefinidas, que tivessem relação direta com as questões vivenciadas no cotidiano dos moradores do projeto, como sexualidade, violência, cidadania, moradia, saúde, marginalização, exclusão, álcool e drogas, por exemplo. Já no primeiro encontro, foram estabelecidas as normas de conduta do grupo e eleitos os principais pontos de discussão, foram apresentados esses temas predefinidos e os participantes puderam fazer sugestões de outros temas, como trabalho, preconceito e relações familiares. Ficou definido que, na divulgação científica/acadêmica do trabalho, seriam usados nomes fictícios, que eles próprios escolheram, e todos os assuntos tratados seriam mantidos em total sigilo.

A cada encontro foi proposta uma atividade inicial, um filme, uma técnica de grupo, uma palestra, um recurso teatral, atividade com fotografia, com recortes de jornais; atividade esta relacionada à temática do encontro e que serviria como disparadora da discussão e reflexão dos participantes sobre o tema. Os temas escolhidos guiaram os encontros, que acabaram possibilitando um processo de amadurecimento de seus membros, a cada rodada de conversas, as trocas de experiências oportunizaram a reconstrução dos elos que se encontravam perdidos.

\section{Discussão dos resultados}

Passados os quinze encontros que se realizaram entre setembro de 2015 e março de 2016, muitas 
palavras foram ditas, muitos assuntos foram objeto de reflexão a partir do tema principal da discussão: os caminhos da autonomia de um grupo de ex-moradores de rua, que sem dúvida vivenciaram muitas histórias, as quais discutimos a seguir.

Desde o início dessa trajetória na busca de uma conscientização sobre o que vem a ser autonomia, ficou claro que muitos já tinham consciência das dificuldades, dos muros que se erguem, altos e difíceis de transpor; obstáculos criados pela sociedade dita democrática de direitos e deveres, mas injusta com aqueles menos afortunados pela herança da sua condição social, como uma das participantes, Luiza, relatou no primeiro encontro, após a atividade de tirar uma foto e narrar o que ela representava:

É uma escada, eu vejo a autonomia como uma escada, e que a gente tem que subir e não tem como a gente chegar no final dela direto. Aí eu quero ter uma televisão de parede a parede, eu também quero ter minha casa, tudo bonitinho, mas não tem como eu ir direto, não tem como chegar diretamente, eu vou ter que subir os degraus, assim que eu vejo a autonomia, vou ter que subir para chegar lá em cima.

Assim, a premissa do grupo foi a troca livre e honesta de ideias, sem a vergonha de se colocar desnudo ante o outro, libertando-se de sentimentos com naturalidade. A autenticidade dos relatos que tanto emocionaram a todos trouxe ao seio desse grupo a identidade que ele tanto necessitava: um grupo que não teve como base somente a reflexão, mas que veio ao encontro da práxis.

Na constituição da identidade, valores e crenças sociais são partilhados, o que mantém os indivíduos próximos de seu tempo e de sua condição - fato que torna evidente que a pessoa é relativa à sociedade em que está. De acordo com Bauman (2005), no mundo contemporâneo "das oportunidades fugazes e das seguranças frágeis” (p. 33) não é mais possível conceber as identidades como se imaginava antes de forma intransigente e sem negociação. No momento atual, elas vêm marcadas por diversas possibilidades de configuração, e o grupo reflexivo contribuiu para que novas configurações identitárias pudessem constituir-se a partir das relações e trocas estabelecidas.

Por mais que exista um assistencialismo sempre pronto a socorrer as almas penadas da sociedade, os invisíveis ou aqueles que não queremos enxergar e que vivem em situação de albergados não têm como chegar à construção do novo sem a vontade de querer ser. E esse querer ser para o ex-morador de rua que ainda está abrigado passa por conseguir estabelecer rede de apoio que o fortaleça no caminho de alcance de suas necessidades de trabalho, justiça, moradia e/ou saúde.

Foi por meio dos assuntos recorrentes nos encontros, nos quais a perspectiva nem sempre era das mais confortáveis, se criou um ambiente favorável para as trocas de ideias e vivências. Ficou claro, em dado momento - quando foi abordada a temática do preconceito -, o quanto os participantes se sentiam perseguidos e estigmatizados pela ordem estabelecida por serem ex-moradores de rua.

Porém o difícil de imaginar é que eles mesmos também reproduzem o preconceito, como no exemplo dado por eles sobre os haitianos que ocupavam o espaço dos moradores no atendimento da rede pública de saúde. Segundo os participantes, isso não era certo, pois tirava o direito destes serem atendidos prontamente. Esse fato, segundo os moradores, fazia com que eles perdessem um tempo enorme em filas, junto com pessoas que não são cidadãs brasileiras. Para eles, os haitianos são um problema do governo e não deles.

Este contexto corrobora a análise feita por Paugam (2003), quando descreve:

Transferir o descrédito para os estrangeiros é um procedimento que permite, a um só tempo, relativizar a inferioridade social - por sua diferença étnica, os estrangeiros estão num degrau ainda mais baixo da hierarquia social, e afastar de modo hábil as reprovações por falha social (p. 260).

Em situações de marginalização e desqualificação pode surgir a necessidade de acusar e pôr a culpa em algo ou alguém - neste caso estudado, culpabilizar os estrangeiros pela falta de um recurso escasso no sistema de saúde desde sempre - pode ser uma maneira de diminuir a condição de marginalização, de olhar para os estrangeiros e sentir que são, de certa maneira, mais vulneráveis que o grupo, que estamos em melhores condições, é também uma maneira de dizer a si mesmo: "não sou um fracasso total, veja como eles estão piores e ainda estão tirando os meus direitos".

Este foi um dos temas recorrentes ao longo de vários encontros: sofrer o preconceito e, ao mesmo tempo, 
reproduzi-lo. Nas falas era comum ouvir coisas como esta que disse Magrão:

Muitas vezes quando vamos arrumar um emprego é necessário ter comprovante de endereço e, quando deixamos o endereço do projeto, as pessoas te olham de rabo de olho, como se fosse gente que não se pode confiar, nós sempre ouvimos: 'Opa! Pera aí! Onde você mora? É um abrigo? Você mora na rua? É da rede de assistência da prefeitura? Ah, tá bom! Olha, assim que eu tiver a resposta eu te ligo, ok?!' É sempre assim que termina uma entrevista.

O nível de conhecimento do grupo em relação à percepção dos efeitos dessas discussões sobre os seus próprios comportamentos foi se evidenciando a cada encontro, tanto pela complexidade dos debates quanto pelo aprofundamento das discussões que era cada vez maior. Mesmo aqueles que inicialmente não participavam dos debates propostos passaram a ganhar forma $\mathrm{e}$ volume no decorrer do processo reflexivo.

A interação tornou-se mais aberta, a revelação de suas experiências com as mazelas da vida, com a violência do cotidiano era trazida de maneira espontânea e contundente, não havia no grupo restrições sobre assuntos como drogas, sexualidade, a vida na rua ou dificuldades em reconhecer os próprios preconceitos, quando o objetivo último era encontrar uma maneira mais adequada de lidar com estes posicionamentos, embora alguns tenham mantido posições mais rígidas e inflexíveis nas suas falas.

Bourdieu (2002) afirma que o "habitus, como indica a palavra, é um conhecimento adquirido e também um haver, um capital" (p. 63). É neste contexto que o grupo toma conhecimento do capital adquirido e do poder de transformar a conjuntura inapta em apta; o construir que estes membros possuem está interligado com sua maneira de lidar com o campo e espaço social, as relações são o conjunto de acontecimentos dentro e fora do projeto, como se comportam diante dos desafios lançados pela realidade que se defrontam, o que traz a conquista de como lidar com o modus operandi de cada membro, e como este reflete para o grupo, como cada um diante das temáticas reage e se percebe.

Durante as reflexões, o posicionamento discordante, muitas vezes, levou à tomada de consciência de fragilidades, dos acontecimentos que antes eram normais e passaram a ter novo significado, o grupo exerceu, assim, influência nas questões particulares de cada membro.

Os diálogos formados nos encontros propiciaram uma escuta favorável à percepção de que os fatores que levam ao preconceito vêm de um conjunto de valores e crenças, nos quais o outro que, muitas vezes, está à margem, tem menos direitos que nós, assim sendo, nós temos prioridade em certas questões como no atendimento nos postos da UBS, como eles acreditavam em relação aos haitianos.

Quando se está diante da própria realidade e ela se torna verossímil, isso pode causar grande incômodo e este foi, por muitas vezes, o tom dos encontros: desafiar o próprio destino, não aceitar de pronto como uma causalidade, como uma vida predestinada ao fracasso, conforme depoimento de Beatriz:

aconteceu um monte de problemas, nós estávamos em um rodeio, era Natal, eu estava com meu filho e ele querendo e vendo um monte de comida e ele querendo, aí um casal de namorados, e ele o Miguel ficou olhando com aquela cara de cachorro pidão e eu ainda grávida e eu não tinha o que fazer, e o casal de namorado deu o sorvete para ele e a gente foi dormir debaixo do palco quando a festa acabou e eu não queria que ele passasse por aquilo, é nessas horas que as pessoas falam: 'calma você tem que respirar'. Mas quando a gente se depara com a realidade, e não tem como, você tem que ir, não pode parar, tem que ir atrás; eu passei fome e queria dividir isso com vocês, eu penso que tudo que a gente passa, por mais triste, por mais difícil que seja, é para deixar a gente mais forte. É como os índios, eles vivem na terra e os pés deles são grossos, se ele pisar na pedra ele vai sentir bem menos que a gente, e acho que a gente passando por este tipo de dificuldade vai deixando nosso pé forte. De repente, quando a gente pisa numa pedra vai fazer menos efeito na gente do que em alguém que mora nessas casas, nesses apartamentos; para eles comer um ovo pode ser a pior coisa do mundo, para gente: 'Hum! Que coisa gostosa!'

Mas não tivemos somente despertares de consciência, o grupo também passou pela dificuldade de enfrentar os seus preconceitos, de perceber o quanto estes eram um entrave para o reconhecimento de que os processos de crescimento do grupo dependiam 
muito da ótica de observação do outro. Neste ponto, tivemos um participante que, apesar de seu posicionamento gerar muito incômodo, foi decisivo para que os outros não tivessem a mesma postura e, o mais interessante, apesar de expressar tanto preconceito e de sua postura extremamente reacionária, em momento algum tivemos uma discussão mais violenta, todos discordavam dele, mas de uma maneira sensata, a discordância era muito comum, principalmente quando o "Mais Velho", como o chamavam, tinha posições como esta:

Que mãe não sabe o filho que tem? É isso, o pai é pedreiro a mãe doméstica, você olha e tem TV de última geração, o melhor sofá que existe, e aí quando a polícia bate lá na porta e diz é aqui que mora fulano de tal? Sim é aqui. Ele está? Sim está dormindo. A polícia entra e leva o cara, a mãe fica: 'Ai, meu filho?'; o policial diz: 'é traficante senhora', o que você mais vê em bar é isso, o cara se achando todo, falando um monte de gíria de malandro, e a mãe não sabe?

Diante de uma fala como essa, a pessoa estaria minimamente em apuros, mas não neste grupo, em que o modus operandi era outro. O que falou mais alto neste grupo foi a autenticidade, todos olharam para o Mais Velho sem esboçar qualquer reação e continuaram a conversar. Embora seja notável lembrar que alguns membros do grupo não concordassem com este posicionamento, e claro, de uma maneira muito sensata discordavam, o que chama atenção aqui é que, de certa maneira, todo o preconceito, toda a amargura com a vida, fez do Mais Velho alguém que, no fundo, acabou ajudando os membros a despertarem para as questões do preconceito, do racismo e da empatia deles próprios.

Quando tratamos da violência, e ela foi representativa para o grupo, pois veio à tona de várias maneiras e facetas, como a violência doméstica, a cotidiana, a do policial agressor e da criminalidade na porta de casa, muito foi dito nos encontros sobre a violência na televisão, no rádio. Eles puderam perceber que não é sempre que a violência está vestida para matar na sua frente, ela se esconde por entre as salas de atendimento dos postos de saúde, dos hospitais, nas filas de espera para ser atendido, no emprego que não se consegue, no comprovante de endereço indesejado pelo empregador.
Para pessoas esquecidas pela sociedade, sem identidade, a violência parece até ser essa que a mídia insiste em mostrar a todos, mas transparece em outras formas mais sutis de ser e de agir, e, desta maneira, o grupo percebeu o tamanho da violência ao seu redor. Como Jamaica falou em seu depoimento:

A violência do descaso social também, a própria sociedade tem o descaso social, não só nos hospitais, em diversas áreas, mas existe a violência psicológica, o descrédito, você precisa de algum serviço na área assistencial, você encontra o funcionário lá com os dois pés em cima da mesa: 'Você senta aí, espera aî.' Você vai na própria UBS, para passar por um atendimento médico é de 4 a 5 horas; são todos: criança, velho, no setor hospitalar, no setor público, é assim no geral.

Não temos porque temer o julgamento que a sociedade faz desta população invisível, desprovida de suporte, muitas vezes desde o início da vida, como lembrou Edna:

um pouquinho da minha vida, com meu pai ele sempre foi correria para tirar a gente da rua, um pouquinho da vida com meu filho, com meu pai sempre foi correria para ter um lugar, eu já fui para albergue com meu filho, já fui para albergue com meu pai, um pouco de tudo, né?! Eu vivi tudo isso, eu dormi com minha filha na rua, ficava deitada no papelão e minha filha ficava colada comigo na minha barriga para ela não ter o contato com o chão.

A partir de temas tão variados, tivemos nossos desarranjos como alguns moradores que tiveram maior dificuldade para interagir diante deste contexto de questionamentos, de conscientização, tanto de cunho individual como grupal. Tivemos casos dentro do grupo de maior resistência aos processos de transformação, muitas vezes acompanhados da rigidez, da falta de condições cognitivas para absorver todas as propostas originadas neste grupo de reflexão e transformadas em ação.

Foi assim com um destes participantes que faleceu em decorrência de uma overdose. Curiosamente, dentre os participantes, foi um daqueles que resistiu muito para interagir, mas quando o fez, foi por inteiro, dentro de suas condições cognitivas, que já 
se encontravam bastante comprometidas. Sendo assim, muitas vezes, dava a impressão de estar fora do tom, mas seu ritmo e harmonia eram diferentes dos demais e, quando se dispôs a participar, ele foi incrivelmente natural. Entretanto perdemos essa batalha, mas ele deixou marcas e contribuiu abundantemente para o grupo.

A busca da plena autonomia não se mostrou um caminho fácil, já que a definimos como algo mutável, indiferente ao espaço-tempo; ela pertence ao momento único de cada dia. Não podemos definir aqui a autonomia como um motivo único, mas sim como uma série de conquistas que levam esta população em específico a ter seus bens materiais, seu teto, seu estudo e, principalmente, a criar uma consciência da sua realidade e de que ela pode e deve ser transformada.

Essa transformação será possível, como afirma Bourdieu (2002), a partir de relações que se organizem em prol de objetivos comuns:

Ora é mais fácil pensar em termos de realidades que podem, por assim dizer, ser vistas claramente, grupo, indivíduos, que pensar em termos de relações. É mais fácil, por exemplo, pensar a diferenciação social como forma de grupos definidos como populações, através da noção de classe, ou mesmo de antagonismos entre esses grupos, que pensá-la como forma de um espaço de relações. Os objetos comuns da pesquisa são realidades que atraem a atenção do investigador por serem 'realidades que se tornam notadas' (Bourdieu, 2002, p. 28).

Tivemos, com essa análise proposta por Bourdieu, a leitura de como se comporta essa população. Esse grupo reflexivo pretendeu promover a troca de sentimentos, emoções e experiências entre os seus participantes; foram essas as realidades que os atraíram e que foram notadas e percebidas.

A partir da objetivação e subjetividade dos participantes, a composição das experiências que viveram no mundo acabou influenciando-os diante das situações que se apresentaram, o quanto se fez presente as crenças herdadas do contexto histórico e a representatividade dos aspectos de vulnerabilidade social, como escreve Bourdieu (2002): "o habitus é um conjunto de conhecimentos adquiridos, são disposições incorporadas ao longo do tempo" (p. 62).
Foi por meio da leitura desse autor que conduzimos a proposta em nosso trabalho, o quanto de capital a população de rua tem em seu poder, o quanto eles podem produzir e que grau de consciência e cidadania podem adquirir.

A análise do comportamento que se relaciona ao habitus vivido se transformou a partir da reflexão questionadora e passou a ser uma ferramenta para o aprendizado em uma nova estrutura social. Importante ressaltar que as relações humanas, até então, caracterizavam-se no campo e espaço social, a partir de uma identidade assumida em condição de vulnerabilidade, cujos fatores preponderantes eram o medo, a insegurança, que se reconfiguram em uma conjectura nova.

Nesse sentido, em um dos encontros - no qual se discutiu sobre os desejos dos participantes e o quanto eles estavam próximos de serem factíveis -, o grande desejo que se apresentou foi o de uma moradia própria. Foi proposto o recurso da expressão teatral, para que eles criassem um roteiro e apresentassem como poderiam realizar tal desejo. A peça se desenrolou dentro do contexto dos moradores do projeto lançando-se em busca de um emprego, o que poderia propiciar esta independência e, com o apoio de outros integrantes, realizar o desejo de ter um espaço próprio para morar.

Na peça, após uma longa caminhada para conseguir um trabalho, veio o inesperado, eles todos se uniram para alugar uma casa em comum, onde cada um teria seu espaço. Foi um pensamento coletivo, não houve - como poderíamos supor - um individualismo de cada um procurar seu próprio local, mas o que era viável e real: unir forças, economias e ter em conjunto um lugar para chamar de seu. Processo que evidenciou como a política pública de assistência social visa funcionar, fortalecendo vínculos, estabelecendo redes de apoio e possibilitando que seus usuários retomem as rédeas de suas vidas.

\section{Considerações finais}

Quando se inicia um projeto não se tem uma ideia clara do que pode acontecer ao longo do processo e talvez um dos maiores desejos do pesquisador seja atingir plenamente seu objetivo, ou seja, que sua hipótese seja de fato confirmada sem nenhum revés.

No caso específico de um trabalho junto a ex-moradores de rua abrigados em um projeto social, os acontecimentos não seguiram o script que tínhamos 
predeterminado. Em um grupo de escuta reflexiva, as nuances dos encontros são dadas pelas experiências de vida de cada participante, não refletindo, muitas vezes, as expectativas do pesquisador. Percebeu-se que não existe, de fato, um controle total do que vai acontecer nesta abordagem grupal.

Ao longo da pesquisa, houve aspectos positivos e negativos, como há em todo trabalho desenvolvido em uma situação real como essa, que existe, mas não deveria existir, pois preliminarmente as pessoas não nasceram para viver em situação de vulnerabilidade social, com suas vidas sempre na corda bamba, obrigadas a serem exímias equilibristas para não caírem no chão das ruas novamente, o que viola qualquer premissa dos direitos humanos.

Um dos objetivos a ser alcançado era a conscientização e a identificação dos problemas nos aspectos sociais e familiares dessa população. A resposta a essa demanda foi trazida e tornou-se objeto de reflexão em todos os encontros, dando margem ao desenvolvimento de um poder de enfrentamento de realidades antes adormecidas que ganharam espaço para tornarem-se visíveis.

Durante esses encontros vieram à tona as dificuldades e os obstáculos que esses moradores precisavam superar. Essas vivências de exclusão, partilhadas com muita autenticidade, criaram as ferramentas necessárias para enfrentar os desafios de se lançarem para uma experiência de cidadãos em seus plenos direitos.

A maneira como foram conduzidas as temáticas e abordadas em sua amplitude e complexidade, trazendo fundamentos para a prática diária das perspectivas elaboradas por cada participante, propiciou ao grupo como um todo uma releitura de suas crenças e valores abrindo caminhos possíveis de serem trilhados em busca de uma vida autônoma, sem o excesso de assistencialismo que congela as atitudes e a vontade do fazer. Pôde-se notar que a individualidade se fundiu à coletividade e à percepção de que a ajuda é sim necessária, mas o caminho só é possível se for trilhado pelos próprios pés, e se for uma caminhada conjunta, melhor ainda.
Neste trabalho, um dos ganhos mais representativos foi a percepção da força que um grupo exerce sobre os indivíduos, deixando de sobressair a opinião individual para dar lugar à voz, à consciência do grupo. Nesse contexto, desenvolveu-se parte desta pesquisa, trazendo à tona algo que antes era praticamente disforme, dando-lhe uma forma, um sentido. A voz comum tem uma propriedade e uma grandeza sem tamanho frente ao individual. Durante este processo reflexivo foi possível observar os participantes conscientizando-se de seus medos, preconceitos, abrindo espaço para novas maneiras de pensar e agir.

Em um cenário no qual há mais de 120 mil pessoas em situação de rua no Brasil - só em São Paulo são mais de 15 mil $^{1}$-, torna-se inviável propor generalizações estatisticamente representativas em uma pesquisa realizada com quinze abrigados de uma instituição, em um universo de 150 pessoas. Entretanto, os resultados da pesquisa permitem afirmar que, para grande parte dos quinze participantes, estar no grupo reflexivo foi relevante para que novos caminhos fossem trilhados. Caminhos que passaram por conseguir um trabalho formal, a internação para tratamento da dependência química, uma nova moradia, consolidando, assim, o principal objetivo deste estudo, que está expresso na pergunta: o que é autonomia para você?

Há muitas respostas a esta pergunta, que variam conforme o momento; podem ser atemporais, circunstanciais, sem uma definição clara e exata, como o vento que sopra para o melhor caminho a se seguir. Contudo, os caminhos da autonomia passarão sempre pela construção de políticas públicas e redes coletivas de apoio que cessem a violação de direitos e viabilizem o exercício pleno da cidadania.

Tendo chegado até aqui, não poderíamos esperar premiação melhor que o convite dos moradores para replicar este projeto com novos participantes. Isso foi possível graças aos que estiveram presentes nos encontros e puderam reconhecer suas potencialidades e se tornaram os protagonistas e verdadeiros autores destes caminhos de autonomia.

\footnotetext{
${ }^{1}$ http://repositorio.ipea.gov.br/bitstream/11058/7289/1/td_2246.pdf
} 


\section{Referências}

Bahia, S. (2010). Como se ser, se não se sabe? O conhecimento como possibilidade de superação em condições de vulnerabilidade. In C. Vaz \& R. Andrade (Orgs.), Território verde e rosa: construções psicossociais no Centro Cultural Cartola (pp. 83-94). Rio de Janeiro, RJ: Cia de Freud.

Bauman, Z. Identidade: entrevista a Benedetto Vecchi. Rio de Janeiro, RJ: Zahar, 2005.

Bourdieu, P. (2002). O poder simbólico. Rio de Janeiro, RJ: Bertrand Brasil.

Castel, R. (1997). As armadilhas da exclusão. In R. Castel, L. Wanderley, \& M. Wanderley, Desigualdade e a questão social (pp. 17-50). São Paulo, SP: Educ.

Castel, R. (1998). As metamorfoses da questão social. Petrópolis, RJ: Vozes.

Coronel, L. (1997). Grupos de reflexão. In D. Zimerman, L. Osório, Como trabalhamos com grupos (pp. 78-79). Porto Alegre, RS: Artes Médicas.

Jodelet, D. (2014). Os processos psicossociais da exclusão. In B. Sawaia (Org.), As artimanhas da exclusão (pp. 55-67). Petrópolis, RJ: Vozes.

Melucci, A. (2004). O jogo do eu. São Leopoldo, RS: Editora Unisinos.

Ministério do Desenvolvimento Social e Combate à Fome. (2009). SUAS. Brasília, DF. http://mds.gov.br/assuntos/ assistencia-social

Paugan, S. (2003). A desqualificação social, ensaio sobre a nova pobreza. São Paulo, SP: Cortez.

Silva, J., \& Corgozinho, J. (2011). Atuação do psicólogo, SUAS/CRAS e psicologia social comunitária: possíveis articulações. Revista Psicologia \& Sociedade; 23(n. spe.), 12-21.

Wanderley, B. M. (2014). Refletindo sobre a noção de exclusão. In B. Sawaia (Org.), As artimanhas da exclusão (pp. 17-27). Petrópolis, RJ: Vozes.

\section{Décio José Moraes}

Graduado em Psicologia pela Universidade Santo Amaro. Psicólogo clínico em dependência química, coordenador de projetos sociais com equipes que atuam junto à população em situação de vulnerabilidade social, São Paulo - SP. Brasil. E-mail: consultordq@uol.com.br

(D) https://orcid.org/0000-0003-1671-4131

\section{Cibele Mariano Vaz de Macêdo}

Psicóloga. Doutora em Psicologia Social pela Universidade do Estado do Rio de Janeiro. Professora do Mestrado em Psicologia, com ênfase em Psicossomática, na Universidade Ibirapuera, São Paulo - SP. Brasil.

E-mail: cibelevaz@gmail.com

(i) http://orcid.org/0000-0002-4130-2115

Endereço para envio de correspondência:

Universidade Ibirapuera. Av. Interlagos, 1.329, 4º andar, Pró-Reitoria de Pós-Graduação, Chácara Flora.

CEP: 04661-100. São Paulo - SP. Brasil.

Recebido 06/03/2018

Aceito 17/12/2018

Received 06/03/2018

Approved 17/12/2018

Recibido 06/03/2018

Aceptado 17/12/2018

Este projeto contou com bolsa de Iniciação Científica da Universidade Santo Amaro. 
Como citar: Moraes, D. J., \& Macêdo, C. M. V. (2020). Caminhos da Autonomia: Grupo Reflexivo com Ex-Moradores de Rua. Psicologia: Ciência e Profissão, 40, 1-13. https:// doi.org/10.1590/1982-3703003192519

How to cite: Moraes, D. J., \& Macêdo, C. M. V. (2020). Paths to Autonomy: Reflexive Groups with Former Homeless People. Psicologia: Ciência e Profissão, 40, 1-13. https://doi.org/10.1590/1982-3703003192519

Cómo citar: Moraes, D. J., \& Macêdo, C. M. V. (2020). Caminos hacia la Autonomía: Grupo Reflexivo con Ex Sin Techo. Psicologia: Ciência e Profissão, 40, 1-13. https://doi.org/10.1590/1982-3703003192519 